\title{
A Study on the Role of Motivation in Foreign Language Learning and Teaching
}

\author{
Abbas Pourhosein Gilakjani \\ Department of English Language Translation, Lahijan Branch, Islamic Azad University, Lahijan, Iran \\ Email: a_p_g48@yahoo.com \\ Lai-Mei Leong \\ School of Educational Studies, USM, Malaysia \\ Email: lmleong@usm,my \\ Narjes Banou Sabouri \\ Roodsar Branch, Payame Noor University, Roodsar, Iran \\ n_sabouri@yahoo.com
}

\begin{abstract}
Motivation has been called the "neglected heart" of language teaching. As teachers, we often forget that all of our learning activities are filtered through our students' motivation. In this sense, students control the flow of the classroom. Without student motivation, there is no pulse, there is no life in the class. When we learn to incorporate direct approaches to generating student motivation in our teaching, we will become happier and more successful teachers. This paper is an attempt to look at EFL learners' motivation in learning a foreign language from a theoretical approach. It includes a definition of the concept, the importance of motivation, specific approaches for generating motivation, difference between integrative and instrumental motivation, difference between intrinsic and extrinsic motivation, factors influencing motivation, and adopting motivational teaching practice.
\end{abstract}

Index Terms - Motivation, Importance, Approaches, Types, Factors

\section{INTRODUCTION}

The success of any action usually depends on the extent to which individuals strive to attain their purpose, along with their desire to do so. In general people have come to refer to this psychological factor - the impulse that generates the action - as motivation. As the term itself indicates, it is a "motive force", something that prompts, incites or stimulates action. To think of motivation as belonging only to the initial stages of an action, - that is as concerned with arousing initial interest and turning it into a decision to engage in some activity - is only a limited understanding of the term. The need to maintain this state of arousal, to determine someone to make the necessary effort to complete an action is also of great importance. This idea is reflected in the definition given by [1] who see motivation as "a state of cognitive and emotional arousal, a state which leads to a conscious decision to act and gives rise to a period of sustained intellectual and/or physical effort." Thus intellect and affect combine with volition and perseverance to result in what is known as motivated behaviour. The same idea is conveyed in different words by Gardner who seems to explain the term with the precision of mathematical demonstration: motivation is a combination of effort plus desire to achieve a goal plus favourable attitudes towards the goal to be accomplished [2].

[2] presents four aspects which make a difference in the success of individuals learning a second language; language aptitude, personality, attitude and motivation. Teachers around the world find that some learners learn more and/or faster than others. Some learners do might want to learn the target language, though, not all. Regardless of the many positive reasons that can be given for learning another language, individuals may perceive things in a different way. There are teachers trying to find ways of making their learners want to learn the target language; thinking of ways to motivate them.

Motivated learners are every teacher's dream - they are willing to work hard, add their own goals to those of the classroom, focus their attention on the tasks at hand, persevere through challenges, do not need continuous encouragement, and may even stimulate others in the classroom, promoting collaborative learning. However, we all know that the motivation behind our learners' learning varies widely, ebbs and flows over the course of the year (or even during a single classroom activity), and stems from various sources, internal to the learner, external, or both. As teachers we can generally see who is motivated and who is not, and often we may wonder how or even if we can harness the motivation of some and spread it out to others. Tapping into motivation is crucial for language teachers because we know that motivation is one of the key factors driving language learning success [3]. In this paper, the researchers discuss the definition of the concept and the importance of motivation, review the specific approaches for 
generating motivation, explain the distinction between integrative and instrumental motivation, elaborate the distinction between intrinsic and extrinsic motivation, mention the factors influencing motivation and demotivating factors identified by [3], and finally state the adoption of motivational teaching practice.

\section{DEFINITION OF MOTIVATION}

There are many different definitions for the term motivation. According to [2], to be motivated, the learner needs to have something to look forward to, a purpose related to goal or objective. This objective would be learning a foreign language. There must be something that the learner wishes to accomplish or gain, being the target language the vehicle to attain it. The learner's reasons for another language could vary from achieving a sense of success, fulfill other's expectations or being able to buy a new car through getting a better job due to command of the target language. [4] states that motivation energises human being and provides direction. Crookes and Schmidt (1991) identify motivation as the learner's orientation with regard to the goal of learning a second language.

According to [5], motivation is defined as "an attribute of the individual describing the psychological qualities underlying behavior with respect to a particular task". This goal-directed behavior shows itself through distinct actions of the motivated individual. [3] described this explicitly when he wrote the following: The motivated individual expends effort, is persistent and attentive to the task at hand, has goals, desires and aspirations, enjoys the activity, experiences reinforcement from success and disappointment from failure, makes attributions concerning success and or failure, is aroused, and makes use of strategies to aid in achieving goals. Motivation should be viewed as a hybrid concept, "an internal attribute that is the result of an external force" [6].

In [4] taxonomy, motivation is comprised of three levels: the language level, the learner level and the learning situation level. The motivation processes at the language level can be described comprehensively by using the traditional concepts of integrative and instrumental motivation; at the learner level motivation involves the influence of various individual traits of language learners, such as, the need for achievement and self-confidence. The learning situation level is also influenced by a number of intrinsic and extrinsic motives. For example, in extrinsic motives, courses are related to the syllabus, the teaching materials, the teaching method and learning tasks. In intrinsic motives, teacher concerns the motivational impact of the teacher's personality, behaviour and teaching style, the group is related to the characteristics of the learner group. In general, motivation is dynamic in nature and can vary from moment to moment depending on the learning context or task.

\section{THE IMPORTANCE OF MOTIVATION IN EFL}

The issue of motivation, particularly in EFL settings, is so important that other considerations about teaching methodology seem to pale in comparison. It is important to think about motivation as the essence of language teaching because of the stark realities of learning English for most of our learners. All of the conditions that we know contribute to successful second language learning are lacking in most EFL contexts: there just isn't enough English input in the environment, there probably aren't enough opportunities for interaction with English speakers, there usually aren't enough strong role models promoting the learning of English, and there may not be widespread enough social acceptance for the idea of becoming proficient in English. Because of these adverse conditions, a learner has extraordinary motivation in order to succeed at learning a foreign language [7].

\section{PARTICULAR APPROACHES FOR GENERATING MOTIVATION}

There are three levels of motivation in language learning that are "operational," or accessible to direct influence by the teacher. To the extent that a teacher can tap into any or all of these levels, he or she is more likely to become a "motivating" teacher.

\section{A. The First Level of Motivation: Finding Learner's Passion}

The first level or the central core of motivation is what might be called "finding your passion." All successful learning is somehow connected to a learner's passion. Passion means a person's central goals in life, the things the learner cares about most, the things that move him or her emotionally. It doesn't mean that a learner needs to become passionate about learning English in order to succeed. Rather, the learner needs to find a way to connect English learning to his or her real passion in life [7].

The teacher can help learners to bring their passion into the classroom in several ways. One is by introducing "hot elements" in the classroom - music, movies, fads, current topics, personalities, games, and so on - in order to trigger learners' real interests. The teacher can use these triggers to build a class culture. If teachers introduce or allow the learners themselves to bring in, samples of current songs, clippings of famous people, or photos or video clips, they invite greater engagement in the classroom. Another way of helping learners find their passion is by organizing class activities around the theme of self-expression. There are a number of approaches here: personalized tasks, idea journals, speaking circles, interactive questionnaires. When learners realize that the content of the class is their personal lives, and that the teacher responds to them as people, not just as language learners, teachers invite a deeper level of commitment and motivation. A third way of generating passion is through the psychological principle of "immediacy" - 
using yourself as a model of enthusiasm and motivation for learning [7].

\section{B. The Second Level of Motivation: Changing Learner's Reality}

In every language learning setting, but particularly in EFL settings, learners cannot make sufficient progress in the L2 because they do not receive enough instruction, not nearly enough attention in class, not nearly enough input or meaningful interaction or opportunities for serious output. A typical learner needs a minimum of four hours a week of quality contact with a language in order to make progress. Even if this estimate is not true for all learners, it is clear to most EFL teachers that learners need more language instruction than teachers can provide in their classrooms. Learners need more quality instruction - input, interaction, and opportunities for meaningful output - not only to make progress, but in order to maintain a sufficiently strong connection to the language and to build their own motivation for learning [7].

Motivation is a major part of teachers' job to help learners find opportunities for engaging learning tasks outside the classroom. Helping learners find quality "homework" is essential to maintain quality learning in the classroom. The ideas are endless: direct learners to quality language learning websites, make available quality audio, video, and multimedia learning sources, develop a small library of accessible readers and supplementary materials and self-access quizzes, worksheets and games. Spending classroom time to help learners select, share, and evaluate their out-of-class work with English is just as important as covering a lesson in the textbook. Helping learners change their reality means moving them toward seeing language learning in a different way. It means helping them take simple, selfdirected steps to make choices about learning. The first step is the most important, because it's the one that can ignite this level of motivation [7].

\section{The Third Level of Motivation: Connecting to Learning Activities}

Connecting refers to the engagement of intention, attention, and memory in the activity itself. All teachers want their students to connect with the learning activities they prepare, yet they often fail to take concrete steps that will lead to better connection. Here are a few "connecting principles" that can be used in teaching materials, such as

- Use personalized warm ups to lead into an activity. This creates relevance - an essential condition for memory to work effectively. Aim to get all learners involved in the warm up.

- Make each learning activity as vivid and tangible as possible. Use provocative topics. Include visual aids (pictures, charts) and tangible references (games, boards, index cards) to engage students' attention. Provide variety in learning activities so that learners can try out different learning styles (interpersonal, kinesthetic, musical, etc.).
- Make sure that each learner is involved, and everyone has an intention in every activity. Assign roles in pair and group activities.

- Include inductive learning in lesson. Be sure that learners have an opportunity to discover things on their own - grammar points, pragmatic patterns, new vocabulary. Give learners a chance to reflect. It's always easier to teach deductively through direct presentations, but discovery learning is more meaningful and more permanent.

- Provide feedback on all levels of language progress. Progress in language involves more than just gradual mastery of grammar and vocabulary. Give feedback on elements of performance that affect learners' motivation: their success in an activity and their level of engagement [7].

\section{THE DIFFERENCE BETWEEN INTEGRATIVE AND INSTRUMENTAL MOTIVATION}

The difference between integrative and instrumental motivation has been made by [8] that has influenced a considerable amount of L2-related research. According to [10] and [2], motivation is divided into two basic types: integrative and instrumental. [8] coined the terms integrative motivation to refer to language learning for personal growth and cultural enrichment, that is the learner desires to learn a language to integrate successfully into the target language community; instrumental motivation is regarded motivation as arising out of a need to learn the L2 for functional or external reasons. These include the achievement of goals, utilitarian purposes for learning such as passing exams, financial rewards, furthering a career or gaining promotion. [4] postulates a motivational construct consisting of an instrumental and integrative motivational subsystem, need for achievement and attribution about past failures.

Both integrative and instrumental motivations are mutually inclusive. Most situations in learning language involve a mixture of each type of motivation. In fact, it difficult to attribute learning language success to certain integrative or instrumental causes. However, the importance of integrative and instrumental motivation depends on situations or contexts, whether learning language functions more as a foreign language or as a second language [9].

\section{THE DIFFERENCE BETWEEN INTRINSIC AND EXTRINSIC MOTIVATION}

The construct of intrinsic and extrinsic motivation theory is defined by [4]. Intrinsic motivation refers to the motivation to engage in an activity because that activity is enjoyable and satisfying to do. Extrinsically motivated learners are those whose actions are carried out to achieve some instrumental end, such as, earning a reward or avoiding a punishment. This internal-external distinction is one that has played a significant part in many current 
theories of motivation. According to [10], who distinguishes five separate dimensions that are considered to comprise motivation, each of which is defined by an intrinsic and extrinsic pole, these concepts have been used to explain differences in motivation between different learners. However, it is hard to consider motivation as something that is either simply internal or external to the learner. For example, learners who study hard to learn L2 may be intrinsically or extrinsically motivated or many have a mixture of both intrinsic and extrinsic reasons prompting them.

Intrinsic and extrinsic construct has a wider distinction from [2] integrative-instrumental motivation. For example, [10] illustrates the relationship between the motivational dichotomies. As extrinsic motivation may turn out to be integrative motivation if someone else wishes the L2 learner to know the L2 for integrative reasons; extrinsic motivation could turn out to be instrumental motivation if an external power wants the L2 learner to learn the L2 language. In addition, intrinsic motivation can turn out to be integrative motivation, if the L2 learner wishes to integrate with the L2 culture; intrinsic motivation can also turn out to be instrumental motivation if the L2 learner wishes to achieve goals utilizing L2. The learners with similar instrumental motivation might show a striking difference between intrinsic and extrinsic motivation. Similarly, the learners with the same integrative motivation can show vast differences of intrinsic and extrinsic motivation. Intrinsic and extrinsic motivation is relevant to integrative and instrumental motivation in relation to $\mathrm{L} 2$ language learning.

\section{FACTORS INFLUENCING MOTIVATION}

\section{A. Motivation and Personality Variables}

Many people see an association between personality attributes and the successful learning of a foreign language. While successful learner may show different types of characteristics (they may be extrovert, selfconfident, active, passive, independent as well as introvert or shy), unsuccessful learners are more frequently described as demonstrating a lack of selfconfidence and being shy, afraid to express their opinions and nervous. Whatever their form of behaviour, learners who try to adopt a more flexible attitude towards the learning of a foreign language seem to have greater chances of success than those whose affective filters are constantly up. Referring to the problem of motivation, [11] has observed that personal motifs such as fear or anxiety may combine with learned social motifs such as a desire for status in a group and for social approval, creating a series of reactions that may inhibit or work towards progress in a foreign language. Up to a point, an anxious learner may try hard to catch up with the group and acquire proficiency in a language. A friendly/supportive environment may be decisive in such a situation. But the judgement of classmates can also be harmful, destroying the self-belief in one's ability to succeed. Combined with a generalized fear of negative evaluation, it may inhibit or distract the learner from the task of attending and remembering new items.

The term "learned helplessness" refers to people who feel that they had no control over their actions and see intelligence as something unchangeable and failure as essentially due to a lack of ability. In conclusion, learners' inhibition may be the result of both internal and external factors, and being related to the ability or inability to find solutions to problems in the past. Another important component influencing motivation to learn is the individual learners' feelings of competence and selfefficacy. Displaying no signs of inhibition, they are usually eager to take risks, are not afraid of making language mistakes and ready to adopt some of the identity characteristics of another cultural group. Their affective filter is low and they can grasp much of the comprehensible input they are faced with. Such people often referred to as "mastery oriented" tend to understand failure in terms of lack of effort and seek to improve their subsequent performance [1].

Given the diversity of personality types, some researchers have tried to find connections between them and receptivity to different aspects of language learning. In a book dedicated to the way in which languages are learned, [12] do not exclude the possibility of motivation to be more related to particular aspects of language proficiency than others. They base their suppositions on several studies among which a language proficiency test in which highly motivated students were found to be more successful in the part of the test which measured oral communication skills but not more successful than others in the part assessing grammatical knowledge. Though, motivated learner may have a better self image and more confidence than non-motivated ones, and such characteristics might make them feel more at ease when interacting with others, the fact that the two things occurred at the same time do not necessarily mean that one caused the other. Even if cases when learners preferred oral practice to written assignments or work on grammatical structure do exist, they cannot make us jump at the conclusion that motivated learners will draw a line between different aspects of a language, accepting some and rejecting others.

\section{B. Attitudes and Motivation}

Most people seem to agree that attitudes and motivation are closely related to success in language learning. This explains perhaps why some people have a much easier time of learning languages than others; in the same classroom setting, some students progress rapidly, while others just struggle along and never achieve command of a second language. [13] has drawn attention to the fact that variables in second language acquisition derive both from the amount of comprehensible input the acquirer receives and understands and from the strength of the affective filter. When the only reason for learning a second language is external pressure, internal motivation may be minimal and attitudes towards learning are likely 
to be negated. On the other hand, if learners have favourable attitudes towards the foreign language and its speakers, towards the teacher and the course, they will probably be more attentive in the class, would take assessments more seriously and, willing to achieve more, would look for situations when they can obtain further practice in the foreign language.

Some critics such as [2] make a distinction between different types of attitudes according to factors in the environment or subject characteristics such as age or sex. Thus we can speak of attitudes revolving around the educational aspects of second language acquisition (educational attitudes) and of social attitudes, focusing on cultural implications of second language acquisition. Sex differences are also thought to influence attitudes and motivation: experience indicates that girls tend to demonstrate significantly more positive attitudes towards learning languages than boys, a good example in this respect being the overwhelming majority in the faculties of philology and foreign languages.

Though many researchers [14]-[1] do not believe in an absolute biological basis for learning, there are cases when differences of age may have an important influence upon the process of foreign language learning. The notion that young children pick up foreign languages more easily than older learners is clearly challenged by the evidence of areas in which the latter do better. However, the adults' emphatic capacity and openness to get involved in "real communication", their ego permeability may be lower especially because of external causes.

\section{THE ROLE OF THE TEACHER IN ALL THE STAGES OF THE MOTIVATIONAL PROCESS}

The role of the teacher is recognized as being highly significant in all the stages of the motivational process. Motivation is no longer thought of only as integrative or instrumental. It is also considered a key to learning something in many cases created, fostered and maintained by an enthusiastic and well-prepared classroom teacher. Because of the importance of the nature of the interactions that occur between learners and teachers, many studies have been dedicated to the discussions of the influence of teachers in the process of foreign language learning. A good teacher should have some important qualities. The first one is the teacher's enthusiasm, acknowledgement and stimulation of students ideas, the creation of a relax and enjoyable atmosphere in the classroom, the presentation of activities in a clear, interesting and motivating way, the encouragement of pupils with difficulties, helping them to increase their expectations of themselves.

[15] has added to all these the importance of (a) making sure the students comprehend every dialogue, utterance, the gist of the reading passage; (b) giving them extensive practice in using verbal or non-verbal alternatives for communicative expressions, structures or language items; (c) correcting important errors tactfully by rephrasing a question, expanding an answer, or by merely saying "listen" and giving the correct answer; (d) letting them either grade their own papers or do so with a partner; (e) showing concern for school or community problems of individuals; (f) making it possible for them to enjoy small successes and the feeling that they are making definite - even if slow - progress toward their goals.

Being constantly aware that all human learning is fundamentally a process involving the making of mistakes may help any teacher in using mistakes and errors creatively during the teaching activity, for they hold in them some of the keys to the understanding of the process. When teachers help the learners to develop an internal sense of control as well as feelings of effectiveness in their ability to carry out tasks, then there are great chances for the learners to become motivated to learn. External reinforcers in the form of rewards, good marks or simple praise, are often considered to be excellent ways of motivating underachieving or reluctant learners. Conversely, extra homework, punishment or other sanctions, proved not only ineffective in bringing about positive change, but also having exactly the opposite effect. As [1] have rightly observed when "feedback actually provides information to learners that enable them to identify specific aspects of their performance, it should prove both motivating and helpful to them to move into the zone of next development. If, on the other hand, the feedback fails to provide this kind of information, it could have entirely the opposite effect."

\section{ADOPTING A MOTIVATIONAL TEACHING PRACTICE}

What makes the classroom climate motivating and how can we increase this characteristic? The motivational character of the classroom is largely a function of the teacher's motivational teaching practice, and is therefore within teachers' explicit control. Therefore, the emphasis in the following analysis will be on conscious strategies that can be used to promote classroom motivation. After the initial motivational conditions have been successfully created-that is, the class is characterized by a safe climate, cohesiveness, and a good student-teacher relationship - the motivational teaching practice needs to be established. This process comprises three phases: (a) generating initial motivation; (b) maintaining and protecting motivation; and (c) encouraging positive retrospective self-evaluation [16].

\section{A. Generating Initial Motivation}

Although many psychologists believe that children are inherently eager to expand their knowledge about the world and, therefore, the learning experience is by definition a source of intrinsic pleasure for them, classroom teachers tend to have perceptions that are in sharp contrast with this idyllic view. Instead of all those keen pupils, all they can often see is rather reluctant youngsters who are totally unaware of the fact that there should be an innate curiosity in them, let alone a desire to learn. And even if we are fortunate to have a class of 
learners with a high degree of academic motivation, we cannot expect all the learners to favor the L2 course over all the other subjects they study. Thus, unless we are singularly fortunate with the composition of our class group, learner motivation will not be automatically there, and we will need to try to actively generate positive learner attitudes toward L2 learning.

There are several facets of creating initial student motivation. [16] has divided these into five broad groups:

1. Enhancing the learners' language-related values and attitudes: Our basic value system greatly determines our preferences and approaches to activities. We can distinguish three types of language-related values: (a) intrinsic value, related to the interest in and anticipated enjoyment of the actual process of learning; (b) integrative value, related to our attitudes toward the L2, its speakers, and the culture it conveys; and (c) instrumental value, related to the perceived practical, pragmatic benefits that the mastery of the L2 might bring about.

2. Increasing the learners' expectancy of success: We do things best if we expect to succeed, and, to turn this statement round, we are unlikely to be motivated to aim for something if we feel we will never get there.

3. Increasing the learners' goal-orientedness: In a typical class, too many learners do not really understand or accept why they are doing a learning activity. Moreover, the official class goal (that is, mastering the course content) may well not be the class group's only goal and in extreme cases may not be a group goal at all.

4. Making the teaching materials relevant for the learners: The core of this issue has been succinctly summarized by [17]: "Educators think students do not care, while the students tell us they do care about learning but are not getting what they need" (p. 38).

5. Creating realistic learner beliefs: It is a peculiar fact of life that most learners will have certain beliefs about language learning, and most of these beliefs are likely to be (at least partly) incorrect. Such false beliefs can then function like time "bombs" at the beginning of a language course because of the inevitable disappointment that is to follow, or can clash with the course methodology and thus hinder progress. Once the main aspects of creating initial student motivation have been identified, it is possible to generate or select a variety of specific classroom techniques to promote the particular dimension [18]-[13].

\section{B. Maintaining and Protecting Motivation}

It is one thing to initially whet the students' appetite with appropriate motivational techniques, but unless motivation is actively maintained and protected, the natural tendency to lose sight of the goal, to get tired or bored of the activity, and to give way to attractive distractions will result in the initial motivation gradually petering out. Therefore, motivation needs to be actively nurtured. The spectrum of motivational strategies relevant to this phase is rather broad (since ongoing human behavior can be modified in so many different ways), and the following six areas appear to be particularly relevant for classroom application:

- making learning stimulating and enjoyable;

- presenting tasks in a motivating way;

- setting specific learner goals;

- protecting the learners' self-esteem and increasing their self-confidence;

- creating learner autonomy;

- promoting self-motivating learner strategies [16].

Self-motivating strategies can be characterized, using [19] words, "as a dynamic system of psychological control processes that protect concentration and directed effort in the face of personal and/or environmental distractions, and so aid learning and performance" (p. 16). That is, they involve ways for the learners to motivate themselves and thereby sustain the action when the initial motivation is flagging. These strategies are particularly important in second language learning because due to the long-lasting nature of the process, L2 learners need to maintain their commitment and effort over a long period, often in the face of adversity.

Based on the pioneering work of [20]-[21]-[22]-[23] and [18] has divided self-motivating strategies into four main classes:

- Commitment control strategies for helping to preserve or increase the learners' original goal commitment (e.g., keeping in mind favorable expectations or positive incentives and rewards; focusing on what would happen if the original intention failed)

- Satiation control strategies for eliminating boredom and adding extra attraction or interest to the task (e.g., adding a twist to the task; using one's fantasy to liven up the task)

- Emotion control strategies for managing disruptive emotional states or moods, and for generating emotions that will be conducive to implementing one's intentions (e.g., self-encouragement; using relaxation and meditation techniques)

- Environmental control strategies for eliminating negative environmental influences and exploiting positive environmental influences by making the environment an ally in the pursuit of a difficult goal (e.g., eliminating distractions; asking friends to help and not to allow one to do something)

An important part of a motivational teaching practice that has a considerable empowering effect is to raise student awareness of relevant strategies and to remind them at appropriate times of their usefulness. 


\section{Encouraging Positive Retrospective Self-Evaluation}

A large body of research has shown that the way learners feel about their past accomplishments and the amount of satisfaction they experience after successful task completion will significantly determine how they approach subsequent learning tasks. The students' appraisal of their past performance depends not only on the absolute, objective level of the success they have achieved but also on how they subjectively interpret their achievement. By using appropriate strategies, teachers can help learners to evaluate their past performance in a more "positive light," take more satisfaction in their successes and progress, and explain their past failures in a constructive way. This latter area is related to the role attributions, which is an issue practicing teachers are usually unfamiliar with even though it has been a central topic in educational psychology [18].

The term attribution has been used in motivational psychology to refer to the explanation people offer about why they were successful or, more importantly, why they failed in the past. Past research had identified a certain hierarchy of the types of attributions people make in terms of their motivating nature. Failure that is ascribed to stable and uncontrollable factors such as low ability has been found to hinder future achievement behavior, whereas failure that is attributed to unstable and controllable factors such as effort is less detrimental in that it can be remedied. Thus, the general recommendation in the literature is to try and promote effort attributions and prevent ability attributions in the students as much as possible. In failure situations, this can be achieved by emphasizing the low effort exerted as being a strong reason for underachievement, and if failure occurs in spite of hard work, we should highlight the inadequacy of the strategies employed. Finally, no account of classroom motivation would be complete without discussing the controversial but very salient effects of various forms of feedback, rewards, and grades dispensed by the teacher. As these are all forms of external evaluation by authority figures, they have a particularly strong impact on the students' self-appraisal [18].

\section{CONCLUSION}

Motivation is a crucial factor in learning a foreign language, which is influenced by different variables: personality variables, the attitudes of learners, their learning styles. Motivation is the 'neglected heart' of our understanding of how to design learning and teaching. Motivation is something all our students bring with them in one form or another. It is not the case that all we need to do as teachers is to identify it, encourage it, feed it now and then, and watch it grow. Rather, our job is also to teach the students how to cultivate motivation, find it in areas where they did not expect it, and reflect upon their own motivational process so they can take charge if it. Many teachers believe that by sticking to the language materials and trying to teach their learners, they will manage to create a classroom environment that will be conducive to learning. These teachers seem to lose sight of the fact that, unless they accept their learners' personalities and work on those small details that constitute their social and psychological make-up, they will fail to motivate them. Therefore, language learning and teaching should take account of a variety of factors that are likely to promote success. Language is part of one's identity and is used to convey this identity to others. Consequently, foreign language learning has an important effect on the social being of the learner, since it involves the adoption of new social and cultural behaviours and ways of thinking.

\section{ACKNOWLEDGEMENT}

I thank Seyedeh Masoumeh Ahmadi, Alizadeh, and Babaei for their extensive and insightful discussions and comments on the paper.

\section{REFERENCES}

[1]. M. Williams and R. Burden, Psychology for Language Teachers, Cambridge University Press, 1997.

[2]. R. C. Gardner, Social Psychology in Second Language Learning, Edward Arnold Ltd, London, Great Britain, 1985.

[3]. Z. Dornyei, "New themes and approaches in second language motivation research," Annual Review of Applied Linguistics, 21, 43-59, 2001.

[4]. Z. Dörnyei, "Conceptualizing motivation in foreign language learning," Language Learning, 40, 46-78, 1998.

[5]. P. D. MacIntyre, K. MacMaster and S. C. Baker, "The convergence of multiple models of motivation for second language learning: Gardner, Pintrich, Kuhl, and McCroskey," In Z. Dornyei \& R. Schmidt (Eds.), Motivation and second language acquisition (Technical Report \#23, pp. 461-492). Honolulu: University of Hawai'i, Second Language Teaching and Curriculum Center, 2001.

[6]. Z. Dörnyei, Attitudes, orientations, and motivations in language learning. Malden, Mass: Blackwell Publishing, 2003.

[7]. M. Rost, Generating Student Motivation. Series Editor of World View, 2006.

[8]. R. C. Gardner and W. Lambert, "Motivational variables in second language acquisition," Canadian Journal of Psychology, 13, 266-272, 1959.

[9]. R. C. Gardner and W. Lambert, Attitudes and motivation in second language learning. Rowley, Mass: Newbury House Publishers, Inc, 1972.

[10]. H. D. Brown, Principles of language learning and teaching. (4th ed.). New York: Addison Wesley Longman, 2000.

[11]. E. L. Deci and R. M. Ryan, Intrinsic motivation and self-determination in human behavior. New York: Plenum Press, 1985. 
[12].S. Harter, "A new self-report scale of intrinsic versus extrinsic orientation in the classroom: Motivational and informational components," Developmental Psychology, 17, 300-312, 1981.

[13]. W. Rivers, "Psychology: Linguistics and Language Teaching," A Forum Anthology, 3-11, 1983.

[14]. P. M. Lightbown and N. Spada, How Languages Are Learned. Oxford University Press, 1993.

[15].S. Krashen, "The critical period for language acquisition and its possible bases," In D. Aaronson and R. Reiber (Eds), Developmental psycholinguistics and communicative disorders (P.66). New York: New York Academy of Sciences, 1975.

[16]. B. Spolsky, Conditions for Second Language Learning. Oxford University press, 1989.

[17]. M. Finocchiaro, "Reflections on the Past, the Present, and the Future", A Forum Anthology, 19-29, 1983.

[18].Z. Dörnyei, Motivational strategies in the language classroom. Cambridge: Cambridge University Press, 2001a.

[19]. B. McCombs and J. Whisler, The learner-centered classroom and school: Strategies for increasing student motivation and achievement. San Francisco, CA: Jossey-Bass, 1997.

[20]. J. E. Brophy, Motivating students to learn. Boston, MA: McGraw-Hill, 1998.

[21]. L. Corno, "The best-laid plans: Modern conceptions of volition and educational research," Educational Researcher, 22, 14-22, 1993.

[22]. J. Kuhl, "Action control: The maintenance of motivational states," In F. Halish \& J. Kuhl (Eds.), Motivation, intention, and volition (pp. 279-291). Berlin: Springer, 1987.

[23]. L. Corno and R. Kanfer, "The role of volition in learning and performance," Review of Research in Education, 19, 301-341, 1993.

\begin{abstract}
Abbas Pourhosein Gilakjani was born in Roodsar, Iran. The author has received B.A. degree in the field of English Language Translation from the Islamic Azad University of Tonekabon Campus, Mazandaran, Iran in February 20, 1993. He has also received M.A. degree in the field of Teaching English as a Foreign Language from the Islamic Azad University of Garmsar Campus, Semnan, Iran in April 23, 1999.
\end{abstract}

$\mathrm{He}$ has been teaching English in the English Translation Department at the Islamic Azad University of Lahijan, Guilan, Iran from 1999 to 2010. He was the Head of English Translation Department from 2007-2009. He is studying Ph.D. in TESOL at the USM, Malaysia. His publications are: (1) The Effect of Information and Communication Technology on Teaching and Learning (India, ELT Weekly Journal, vol.3 Issue\#79 January, 17, 2011. (2) Role of Consciousness in Second Language Acquisition (Finland, TPLS Journal, Issue 5, May, 2011. (3) Why Is Pronunciation So Difficult To Learn? (Canada, ELT Journal, vol. 4, no. 3, September, 2011). (4)
Multimedia and Its Effect on the Quality of English Language Teaching (Indonesia, Celt, Vol. 11, No. 1, pp. 14-35, 2011.

His main interests are English pronunciation instruction, speaking skill, listening skill, technology, motivation, and reading comprehension skill.

Mr. Pourhosein Gilakjani is the Faculty Member of the Islamic Azad University of Lahijan, Iran.

Lai-Mei Leong is a senior lecturer at the School of Educational Studies, Universiti Sains Malaysia. Her fields of expertise include ICT in Education and English Language Teaching.

Narjes Banou Sabouri is the Faculty Member of the Payame Noor University, Roudsar, Iran. Her field of expertise is linguistics. 